\title{
PALAVRA ABERTA - O LEGADO DA OBRA DE PAULO FREIRE PARA A EDUCAÇÃO GLOBAL CONTRA-HEGEMÔNICA
}

RESUM0: A autora explicita tomar para si, neste texto, o conceito de hegemonia sob a perspectiva de Antônio Gramsci. Ela discorre sobre educação hegemônica e educação contra-hegemônica e aponta a substantiva diferença entre uma e outra que são compreensões antagônicas. A autora assevera que Paulo Freire, na sua pedagogia ou compreensão de educação ético-estético-antropológico-política, concebeu uma educação contrahegemônica e conclui que a obra pedagógica de Paulo Freire canaliza seus princípios, conceitos, relações, prática e práxis na direção de uma educação contra-hegemônica desde a sua origem. A obra é radicalmente contra os interesses dominantes, e em qualquer das esferas da vida social, a favor das camadas subalternas, dominadas.

Palavras-chave: Paulo Freire. Educação. Hegemonia. Práxis.

\section{OPEN WORD - THE LEGACY OF PAULO FREIRE'S WORK FOR GLOBAL COUNTER HEGEMONIC EDUCATION}

ABSTRACT: The author explicitly takes to herself, in this paper, the concept of hegemony from Antonio Gramsci's perspective. It discusses hegemonic education and counter hegemonic education. It points out the substantive difference between one and the other which are antagonistic understandings. She claims that Paulo Freire in his pedagogy or understanding of ethicalaesthetic-anthropological-political education conceived a counter hegemonic education. The author concludes that Freire's pedagogical work channels its principles, concepts, relations, practice and praxis towards a counter hegemonic education since its origin. Freire's work is radically opposed to the dominant interests, and in any of the spheres of social life in favor of the subortinated, dominated sectors.

Keywords: Paulo Freire. Education. Hegemony. Praxis.

'Pontifícia Universidade Católica de São Paulo, São Paulo, SP, Brasil.

" Doutora em Educação pela Pontifícia Universidade Católica de São Paulo (PUC-SP). 


\section{ALGUMAS PALAVRAS PRELIMINARES}

O que é hegemonia? A hegemonia é um conceito existente desde a antiguidade, mas desenvolvido por Antônio Gramsci, no século XX. O que é educação hegemônica e educação contrahegemônica? A educação hegemônica é aquela que procura orientar a educação no sentido da conservação da sociedade em que se insere, mantendo a ordem existente, em correspondência aos interesses dominantes e que tende a hegemonizar o campo educativo.

A educação contra-hegemônica ${ }^{1}$ é aquela que busca orientar a educação, tendo em vista a transformação da sociedade, posicionandose contra a ordem existente, que busca intencional e sistematicamente colocar a educação a serviço das forças que lutam para transformar a ordem vigente, visando instaurar uma nova forma de sociedade. ${ }^{2}$

\footnotetext{
Hegemonia é o conjunto das funções de domínio e direção exercido por uma classe social dominante, no decurso de um período, sobre outra classe social e até sobre o conjunto das classes da sociedade. A hegemonia é composta de duas funções: função de domínio e função de direção intelectual e moral, ou função própria de hegemonia (MOCHCOVITCH, 1992, p. 20-21)
}

Propõe Paulo Freire na sua pedagogia ou compreensão de educação ético-antropológico-política uma educação contrahegemônica? Afirmo que sim. Seguem meus argumentos de comprovação. Suas ideias pedagógicas "revolucionárias" foram percebidas, como ele mesmo dizia, pelos seus vizinhos da esquerda, depois dos da direita, imediatamente depois pelos vizinhos da frente e pelos de trás de sua casa, no Recife ainda nos anos 1950.

Antes de tornar-me um cidadão do mundo fui e sou um cidadão do Recife, a que cheguei a partir de meu quintal, no bairro de Casa Amarela. Quanto mais enraizado na minha localidade, tanto mais possibilidades tenho de me espraiar, me mundializar. Ninguém se torna local a partir do universal. O caminho existencial é inverso. Eu não sou antes brasileiro para depois ser recifense. Sou primeiro recifense, pernambucano, nordestino. Depois, brasileiro, latino americano, gente do mundo. (FREIRE, 2012, p. 25)

É verdade, de um simples professor de língua portuguesa, do Recife, formado no curso de Direito, adentrou em si mesmo e percebeu, claramente, que queria continuar a ser educador como vinha sendo, no lugar de ser um advogado como tinha direito. Penetrou na difícil arte de educar e, por suas qualidades pessoais, sonhou com um mundo novo a partir de mulheres e homens novos. Tornou-se, ao aumentar o seu âmbito e profundidade de atuação, um dos maiores educadores do mundo, em toda a história da humanidade. Hoje é Patrono da Educação Brasileira. 
Suas reflexões o levaram a compreender a terrível miséria de homens e mulheres dos mocambos e alagados de sua cidade que se consideravam "sombras dos outros". Por que pensam de si mesmos como autodemitidos da vida? - perguntava-se Paulo.

Porque, admitiu, primeiramente como hipótese, eles são privados de um direito ontológico, o de todos os seres humanos: ler e escrever a palavra. Asseverou depois, esse direito é ontológico porque decorrente de que foram os homens e as mulheres que inventaram, em comunidade, coletivamente, a linguagem oral e depois a linguagem escrita; esse ato é, portanto, um direito ontológico dos seres humanos. Esse direito negado, nega o amor próprio aos analfabetos. Rouba-lhe a humanidade.

Paulo entendeu neste momento que um mundo novo só poderia erigir-se de homens e mulheres SERES MAIS. Sujeitos e não só objetos da sociedade e de si mesmos, não com indivíduos "demitidos da vida", mas com pessoas SERES MAIS. Então, para chegar a homens e mulheres sujeitos de si, Paulo lutou, sobretudo depois que compôs dentro de sua teoria educacional um Método de Alfabetização, para que, além de ler e escrever a palavra, os(as) alfabetizandos/as soubessem, criticamente, ler o mundo. Esse é o ato de conscientização, que precisa da escola oferecida pela educação formal.

Paulo partiu, então, da mais radicalmente possível realidade recifense, nordestina e de sua experiência pessoal, acrescida de sua imensa curiosidade e criatividade inventiva para compor uma teoria do conhecimento ético-político-antropológico-social da educação. Teoria que teve sua intenção primeira na alfabetização do povo recifense/pernambucano.

Essa caraterística do enraizamento local e existencial de Paulo e, consequentemente, por sua extrema coerência entre sua vida e obra, sempre buscando e procurando a substantividade das coisas e dos fenômenos, que precisam da consciência crítica incidindo na realidade concreta, que lhe deu a prerrogativa de um pensar a educação absolutamente novo. Este pensar negava (nega) as formas antigas da aprendizagem do conhecimento, quando se acreditava que a mesma se dava pela repetição mecânica das palavras e das frases. E também pelo castigo, pela punição corporal. A esta didática do não aprender Paulo deu o nome de educação bancária.

Criou uma compreensão de educação que atendia os desejos, as aspirações e as necessidades das diversas pessoas da sociedade, alijadas das elites. Aí percebeu a luta de classes e as condições e as relações da opressão de classe. Posteriormente, as de gênero, de religião, das opções diferentes de sexualidade, etc. 
Lembrando-se da sua própria pobreza e das análises teóricas da opressão, da exploração, do elitismo e da discriminação contra a população destituída dos bens culturais e materiais do entorno onde vivia - Recife e Jaboatão, com seus contextos concretos - Paulo criou uma compreensão de educação autenticamente humanista e libertadora. Problematizadora. Partiu das virtudes nascidas com ele, dentro dele, mas que as foi aperfeiçoando como homem sensível, preocupado com o outro e a outra no trato social. Fez delas, ao lado da valorização da intuição e do senso comum, o ponto central, nevrálgico, de suas reflexões para criar essa teoria. Assim, submeteu essas categorias à reflexão radical crítica e fez das suas virtudes de vida as categorias fundamentais da sua compreensão crítica de educação. Em outras palavras, Paulo jamais dicotomizou emoção e sentimentos da razão reflexiva. Superou a intuição e o senso comum na construção das ciências e da filosofia e até do conhecimento religioso. Privilegiou a prática, porque é ela que dá à teoria a condição de Verdade. Para ele, teoria-prática é uma unidade indissolúvel na construção do saber.

Nunca trabalhou sobre as ideias de outros filósofos ou educadores porque preferia sempre ousar, buscar a interpretação da realidade e criar do que fazer especulações sobre os ditos e os feitos por outros e outras. Tinha verdadeira fascinação para entender as coisas novas, pensar sobre as dúvidas. Estas o levaram sempre a levantar hipóteses e a aprofundar mais ainda o seu pensar, num movimento dialético, do qual compreendia os inéditos-viáveis que nutriam seus sonhos, os sonhos humanos possíveis diante da incompletude humana.

Incompletude que nos "obriga a movermo-nos" no mundo, perseguindo e, ao mesmo tempo, forjando a esperança, na busca do inédito viável, da utopia, dos sonhos possíveis e dos sonhos que fazemos possíveis para tornamo-nos Seres Mais e construirmos um mundo melhor.

Paulo leu cientistas, filósofos, sociólogos, teólogos de todas as matrizes. Valorizou os que se coadunavam com seu espírito inventivo, criativo e curioso, adentrou na fenomenologia, na dialética marxista, no personalismo e, anos depois, na Teologia da Libertação. Nunca deixou sua curiosidade "dormir"; sempre atendeu às suas intuições; valorizou o senso comum; prestava atenção ao seu corpo, porque sabia que nosso corpo é corpo consciente. Dizia a si próprio: "Paulo, incida sua reflexão nisso e naquilo", no momento em que seus pelos se irisavam, seu rosto ficava ruborizado e sentia a taquicardia no seu peito. Sinais de que o seu corpo consciente indicava que ele precisava refletir sobre o que seu corpo sensível the expunha, que adivinhava que algo importante estava para ser percebido e comunicado. Com 
outras palavras: Paulo explicitava o evento dando-lhe consistência científica ou filosófica etc., o nomeava com a palavra certa, objetificando-o para, por fim, comunicá-lo.

O diálogo freiriano se propõe a abrir as possibilidades de entendermos que só lemos verdadeiramente um texto se formos lendo o contexto de quem o escreveu, relacionando-o com o nosso, o contexto de quem está lendo o texto. Fora dessa relação dialética vivencial texto-contexto-diálogo não pode haver a compreensão precisa, clara, verdadeira nem das palavras pronunciadas ou escritas, nem do contexto do mundo a que as palavras estão a se referir. Falta a dobradiça, a ligadura, a "alma”, que produz tal compreensão; o diálogo, prenhe de curiosidade, de dúvidas, de hipóteses, sem determinismos, sem arrogância, sem a prioris, torna-se o ato fundamental, o centro da busca. Por isso, só o diálogo como Paulo o concebeu nos provoca a ler o texto com relação ao contexto e, em última instância, nos conduz ao caminho da possibilidade da libertação, que nega a globalização e o neoliberalismo, autores de muitas das mazelas que sofremos, todos do mundo, atualmente.

Só o diálogo como Paulo o entendeu, sério e rigoroso, nos impede das certezas estreitas e limitantes das interpretações do mundo e da Verdade e nos introduz no complexo "mundo das possibilidades", dando abertura e coragem para entrarmos no mundo da criação, da ousadia e da invenção. Só o diálogo freiriano sério e rigoroso propõe ler o texto lendo "obrigatoriamente" o contexto.

O diálogo freiriano vai à raiz mais profunda das coisas para explicar, temporária, porque a Verdade é histórica, e criticamente, a realidade concreta. O diálogo freiriano prioriza a pergunta que faz pensar e voltar a ela com uma nova pergunta, não a resposta pronta, espontânea e sem reflexão.

A leitura de mundo de Paulo, que funda e constitui a sua teoria crítica, parte do diálogo e leva à conscientização. $\mathrm{O}$ verdadeiro diálogo abre, portanto, a possibilidade do engajamento na transformação da sociedade, perguntando-nos e induzindo as outras pessoas a perguntarem-se: por quê? Contra que e contra quem? A favor de que e de quem?

Na dialogicidade, a dialeticidade implica a relação subjetividadeobjetividade na compreensão do mundo, no ato educativo. Isto é, ser curioso na busca do conhecer mais, cientificamente, e autenticar-se ao respeitar as diversidades étnicas, raciais, de gênero, de religião, de língua e linguagem culturais; e ser generoso e tolerante na participação do outro (a) com suas diferenças pessoais e culturais. 
Paulo entendeu a dialogicidade, na relação subjetividadeobjetividade inovadora e dialeticamente, afastando-se, assim, da maiêutica socrática e da dialética mecanicista, apresentando uma compreensão do mundo/ato de educar e de conhecer verdadeiramente o saber, possibilitando criarem-se novos saberes para interferir no mundo, no sentido de torná-lo melhor e mais justo. Diálogo que implica, pois, numa relação dialética entre os pares que dialogam (as subjetividades) e a objetividade do objeto cognoscível, em foco.

A dialogicidade tem a ver, portanto, com a relação com o Ser curioso/curiosidade epistemológica, com o autenticar-se/ autenticidade na troca de afetos e saberes que provoca mais afetos e saberes e com o respeitar-se/ respeitar outro (a) nas suas diferenças, e o mundo. Com o TU que promove a percepção do EU. Com o serse generoso/generosidade no participar/participação. Isto é, que sua curiosidade na busca do conhecer mais cientificamente saiba respeitar as diversidades étnicas, de gênero, de religião, de língua e linguagem culturais; e ser generoso na oportunização da participação do outro (a) nas decisões e ações, com suas diferenças pessoais e culturais.

A dialogicidade freiriana, porque comunicadora e comunicante, possibilita, o conhecimento que promove a humanização, e esta, a libertação de todos e todas sob a égide da tolerância, que não pode ser confundida com conivência.

A comunicação freiriana "ensopa" é um dos fundamentos da compreensão de educação de meu marido. A que sustenta a autêntica educação e se nutre do sonho possível, da utopia, que nos coloca como homens e mulheres donos de nossos destinos humanos. A que pode, pela conscientização (que o diálogo da comunicação verdadeira oferece), abrir possibilidades de um outro mundo. A que nos aponta e indica, enfim, que podemos pôr em prática uma outra educação pautada pelos princípios políticos e éticos, tanto quanto pelos pedagógicos e epistemológicos, aqueles que valorizam e dignificam todos os homens e mulheres.

A politicidade como outro fundamento da teoria e da práxis de Paulo Freire, explicita a natureza política da educação, negando a neutralidade no ato educativo. Tem sua relação com a conscientização. Isto é, leva os indivíduos a se conscientizarem do fato de que o educador (a) de toda natureza quer mudar e agir com esse objetivo como um projeto de vida. Portanto, quer comprometerse com a superação das injustiças sociais de toda sorte que nascem, sobretudo com as diferenciações dos níveis de educação de modo geral e não só pela qualidade de ensino escolar posta à disposição (ou até não posta) para a população nacional. Solidarizar-se com os 
oprimidos e excluídos no processo educacional, mas sobretudo, nas possibilidades de inserção deles nos destinos de seu país. Lutando ousadamente, correndo riscos com os oprimidos e excluídos para que, pela educação, eles (as) saiam do nível de compreensão mágica, mítica ou ingênua do mundo para se apropriarem, num processo permanente, do nível de consciência crítica que a educação como ação cultural crítico-dialógica pode oferecer. Essa que dá voz à mudez, que pronuncia o mundo (no lugar dos blábláblás dos comunicados "sloganizados"), que devolve ou cria a possibilidade de restaurar a ontológica humanidade roubada dos oprimidos.

Em Paulo, suas palavras que pronunciam o mundo têm dentro delas mesmas a sua natureza ética libertadora, estão carregadas no mais íntimo delas da natureza ética mais profunda que habitou intencionalmente nele. Daí que palavra para Paulo é práxis libertadora, pois nelas, nas palavras dele, estão a dinâmica da práxis, a intenção da Verdade que só a práxis eticamente correta tem. Ética em Paulo é a ética da Vida, a ética universal do ser humano.

O discurso da globalização que fala da ética esconde, porém, que a sua é a ética do mercado e não a ética universal do ser humano, pela qual devemos lutar bravamente se optamos, na verdade, por um mundo de gente. O discurso da globalização astutamente oculta ou nela busca penumbrar a reedição intensificada ao máximo, mesmo que modificada, da medonha malvadez com que o capitalismo aparece na história. O discurso ideológico da globalização procura disfarçar que ela vem robustecendo a riqueza de uns poucos e verticalizando a pobreza e a miséria de milhões. O sistema capitalista alcança no neoliberalismo globalizante o máximo da eficácia de sua malvadez intrínseca. (FREIRE, 2011, p. 127-128).

A educação hegemônica se alinha com essa postura que é própria do neoliberalismo globalizante, que desrespeita os que pouco ou nada têm.

A compreensão de educação de Paulo (ou a sua epistemologia ou ainda com outras palavras a sua teoria do conhecimento), partindo da sua eticidade mais radical, forjada nele por ele mesmo em estágio anterior aos seus estudos das teorias pedagógicas, políticas, antropológicas, filosóficas e sociológicas, precisa ser vista, sobretudo por sua coerência existencial e científica, como uma proposta, como um paradigma ético. Como um paradigma para a educação libertadora. Como um paradigma para a solidificação da Paz, para a sustentabilidade do Planeta Terra e para a plenificação da Vida e da autêntica democracia.

Daí ter Ernani Maria Fiori escrito: "Paulo Freire é um pensador comprometido com a vida: não pensa ideias, pensa a existência" (FREIRE, 1987, p. 11) 
Paulo acreditou na comunhão entre homens e mulheres e na ressurreição de nossa substantividade ontológica. Mostrou-nos sem prescrições ou ordenações como se pode e porque devemos lutar ousadamente, enquanto educadores e educadoras, correndo riscos, com os oprimidos(as) e excluídos(as), para que eles(as) possam sair do nível de compreensão mágica, mítica ou ingênua do mundo ou do estágio de impotentes diante da cultura de opressão e da repressão dos dominantes do mundo para se apropriarem, num processo permanente de cognoscibilidade e afetividade, do nível de consciência crítica, que só uma educação como ação cultural dialógica e de comunicação verdadeira, pode oferecer.

Paulo desvelou a face oculta das coisas cobertas pelas ideologias sem ansiedade, pacientemente impaciente. Reconheceu seus resvalamentos e seus próprios erros com a mesma naturalidade com que foi "des-cobrindo" algumas obviedades ainda não apreendidas ou entendidas na história. Procurou sem tréguas a coerência entre o que pensava, dizia, fazia e escrevia. Deu seu sim à rebeldia e seu não à resignação. Valorizou a ciência sem menosprezar ou diminuir o senso comum, antes o considerando ponto de partida para aquela. Entendeu o erro como fase da construção do saber. Negou veementemente o treinamento no lugar da formação. Desmantelou convicções marxistas, ao afirmar que a história é possibilidade e não determinismo. Proclamou sua descrença no fatalismo e teve fé nos homens e mulheres para construírem a história segundo seus próprios anseios, lutas, sonhos, projetos e necessidades.

Sistematizou e valorizou a curiosidade. A espontânea, que pode levar à curiosidade epistemológica. No processo de busca do conhecer não omitia suas opções, dúvidas, indecisões e decisões, que, ele reconhecia, implicam em rupturas e dores. Socializou e procurou convencer os outros e as outras sem jamais impor, prescrever ou resolver por eles ou elas, as suas dúvidas, sonhos ou problemas. Optou pela diretividade sem autoritarismos, propondo sempre a comunicação que se produz no diálogo como princípio fundante da educação crítica libertadora. Nunca confundiu diretividade com doutrinação.

$\mathrm{Na}$ pedagogia de Paulo, a diferença é o princípio do diálogo entre o EU e o TU, portanto, para o aperfeiçoamento das virtudes pessoais éticas e políticas, para o conhecer e o saber interferir no mundo. A dialogicidade em Paulo tem, portanto, imbricadas dialeticamente as dimensões epistemológica e política, ética e estética, além da cognoscitiva e psicossocial-histórica. 
Paulo refletia em profundidade o que ouvia, lia ou via, vivendo dialeticamente tudo na sua razão/emoção como uma instância única do seu ser e da rigorosidade que a Verdade exige enquanto tal. Dava-se o direito de sentir profundamente as raivas, legítimas, como dizia, então elaborava o acontecido científica e politicamente, perguntando-se sempre, nos seus dizeres pautados pela compostura ética irrepreensível, sempre a favor dos oprimidos e das oprimidas através de uma criação linguístico-estética de rara beleza. Assim, quando repudiava o feito ou o fato, os denunciava, daí, dialeticamente, brotava, amorosamente, o anúncio, o novo. Essa é a dinâmica da denúncia-anúncio em Paulo, como educador político-ético. A sua maneira de autenticamente aproximar-se das "vítimas" e dos oprimidos.

Aproximar-se das vítimas não só para entendê-las sob o ponto de vista político-cognitivo-epistemológico, mas também sob o ponto de vista existencial, afetivo e emocional. De ir ensinando, a partir do aprendido com esses e essas, não com recados prontos do educador. Ato que, ao cuidar deles e delas, com eles e elas, faz emergirem todos como novos sujeitos sociais.

A sua teoria da ação dialógica comunicativa nos demonstra que seus sonhos não são devaneios idealistas, são propostas político-éticas reais, libertadoras. Seus sonhos de uma sociedade verdadeiramente ética e politicamente justa são, portanto, sonhos possíveis que precisamos e devemos concretizar. Devemos e precisamos para isso arregaçar as mangas, pois ainda há tempo de nos fazermos cidadãos do mundo a serviço de um mundo melhor. Mundo onde caberão, com dignidade e respeito, a diversidade cultural das mais diferentes vivências e leituras de mundo com seus consensos e dissensos, de crianças, mulheres e homens negros, brancos, amarelos e vermelhos; ricos e pobres; muçulmanos, cristãos, evangélicos ou judeus; homossexuais, heterossexuais, bissexuais, transexuais e transgêneros. Esse Mundo justo e de Paz é o Mundo da utopia democrática pela qual Paulo lutou por toda a sua vida.

Afirmo, enfim, que a obra pedagógica de Paulo Freire canaliza seus princípios, conceitos e práxis para uma educação contrahegemônica desde a sua origem, pois ela é radicalmente contra os interesses dominantes, e, em qualquer das esferas da vida social, a favor das camadas subalternas, dominadas.

A educação baseada neste legado de Paulo é, portanto, capaz, eficiente e necessária de ser tomada para subsidiar a educação de qualquer país que quer se fazer democrático diante de seus princípios universais. Entretanto, é condição que as pessoas que decidem a política educacional ensejem uma educação eminentemente política, estejam dentro do 
universo da ética e da estética centrada na dignificação dos sujeitos históricos, homens e mulheres, respeitando-os como SERES MAIS.

A ética da vida de Paulo Freire, quero enfatizar, tem como intuito possibilitar a libertação e a autonomia dos sujeitos históricos; é marcada pela possibilidade política da transformação da sociedade em direção a uma realidade mais justa e ética. A uma sociedade verdadeiramente democrática.

Acredito que a minha exposição sobre a práxis e o pensamento político-ético-antropológico-pedagógico-social de Paulo Freire, contido em toda a sua literatura, responde à questão formulada para esse "Diálogo". Afirmo, portanto:

"O legado da obra de Paulo Freire continua vivo e é adequado e eficiente, responde, enfaticamente, às necessidades da educação global contra-hegemônica". Por antinomia não serve à educação hegemônica, mas, em contradição com esta, atende, plenamente, a todas as políticas educacionais, de qualquer parte do mundo, que faça a opção progressista, libertadora, a que pode transformar essa comunidade, numa sociedade autenticamente democrática.

\section{REFERÊNCIAS}

FREIRE, Paulo. Pedagogia da autonomia: saberes necessários à prática educativa. São Paulo, Paz e Terra, 2011.

FREIRE, Paulo. Pedagogia do Oprimido. Rio de Janeiro, Paz e Terra, 1087.

FREIRE, Paulo. À sombra desta mangueira. São Paulo, Paz e Terra, 2012.

MOCHCOVITCH, Luna Galano. Gramsci e a Escola. São Paulo, Atica, 1992.

\section{NOTAS}

\footnotetext{
${ }^{1}$ Segundo o mesmo autor, situam-se nesse âmbito as pedagogias: socialista, libertária, comunista, libertadora, histórico-crítica. A pedagogia de Paulo estaria no âmbito da educação libertadora.

${ }^{2}$ Ver em História das Ideias Pedagógicas no Brasil de Demerval Saviani.
}

Submetido: 21/12/2018

Aprovado: 15/02/2019

Contato:

Editora Villa das Letras Rua Hércules Mazzoni, 1195

Indaiatuba $|\mathrm{SP}|$ Brasil

CEP 13.330-250 